\title{
Cognitive ability and the light bulb
}

\section{The road to the stars has also illuminated the human mind}

\section{Brian Aldiss}

$\mathrm{T}$ he arrival of the spaceship Conqueror into Arcopian space proves ironic. However, it provides us with an opportunity to look back on our distant predecessors and understand something of their combative and rickety societies.

Once the dead bodies had been cleared from the Conqueror, and preserved in our museums, mechs were dispatched to examine the ship as part of our phylogenetic record.

The ship was fitted with old-fashioned quantum computers. The Conqueror had left the old Solar System late in 2095. It carried 10,000 human embryos in cryogenic conditions, and several million embryos, similarly frozen, of terrestrial animal genera, together with numerous plant species. There were also $20 \mathrm{crew}$, supported by anti-thanatonic drugs.

Technologists had designed the ship to accelerate to 12 per cent of the speed of light. By their computations, it was due to reach this system (where only two planets capable of supporting carbon-based life had been identified) in 196 years. The power source was a fusion engine.

In those rather primitive days, attention concentrated on the hardware. It was the bacteria on the Conqueror that brought about disaster, killing crew and embryos alike.

Subsequent advances in radiotelescopy revealed no fewer than 15 planets orbiting the Arcopia main-sequence sun, of which five had environments suitable for life. In the Second Renaissance of the early twentysecond century, the spiritual order of God's Exiles perfected an ion drive and equipped another interstellar ship, Pilgrim. Pilgrim was launched from plutonian orbit in 2151 . It carried with it the embryos of new species of animals, fruits and human beings. The entire journey was governed by quantors - God's Exiles did not inflict years of imprisonment on humans, as the Conqueror had done.

This journey took 138 years to complete. Thus the arrival was in 2289, two years before the Conqueror reached us, despite starting 56 years later.

In these improved drives we see symbols of the expansion of human consciousness. Everything is subject to change, and living things to evolutionary change, marking their passage through time. Study of the evolution of human consciousness was scarcely recog- nized as a discipline until interstellar flight proved to speed conceptual processes. The necessity for understanding and dealing with totally new environments was responsible for this rapid acceleration in human mentation. A similar acceleration is recorded some 40,200 years ago in Europe, when fresh environments brought about a great expansion in the metaphors of art and sculpture - all of which represent an upward surge in cognitive ability.

To produce art or science is to experience a coming together of previously somewhat isolated faculties, which combine to make a greater whole. Another well-known example of such a quantal happening is the First Renaissance, a time of great advances in art, science, warfare and political management.

In describing these advances, twentysecond-century philosopher Almond Kunzel famously deployed an analogy between human consciousness and an antique, incandescent light bulb. Early consciousness could be likened to a 40-watt bulb - sufficient, dimly, to illumine a room, but insufficient to study details by. The First Renaissance marks a shift in brightness to 60 watts. Much more can be discerned, although illumination is not cast very far.

With the twentieth century, often referred to as the Savage Century, owing to its horrifying record of war, threats of war and genocide, the bulb brightens to 100 watts. Despite the savagery, humanity is for the first time developing a form of remote awareness (remware, as we know it) to aid its exploration of all environments.

Those environments included, of course, the Solar System to which our predecessors were then confined, and also the human brain. The brain was almost completely mapped by the end of the Savage Century. With the ability to genetically engineer brain function, many irregularities - caused by the piecemeal nature of this organ as naturally evolved - were eradicated. Clearer thinking emerged. Humanity outgrew war.

We have now reached the stage of, in Kunzel's terms, the 1,000-watt brain. Our offspring are born with an understanding of fractals.

This great expansion of cognitive ability led to the new perception of the Universe as a series of contiguities, and to the construction, in the year 2162, of the photon drive. The fleet of ships launched in 2200 arrived here in the planetary system of Arcopia the following year.

Our culture was thus firmly established when the old ships of 2095 and 2151 arrived, fossils of a former time. They harbour, in orbits far from the planet on which humanity began, memories of bygone ages - long before there was even a light bulb to light our way. Records on these gallant old hulks demonstrate how, sadly, the human world once contained less order, less joy and less fulfilment than now.

Brian Aldiss is a novelist and critic. His latest book is a utopia, written in collaboration with Roger Penrose, entitled White Mars, Or The Mind Set Free (Little, Brown).

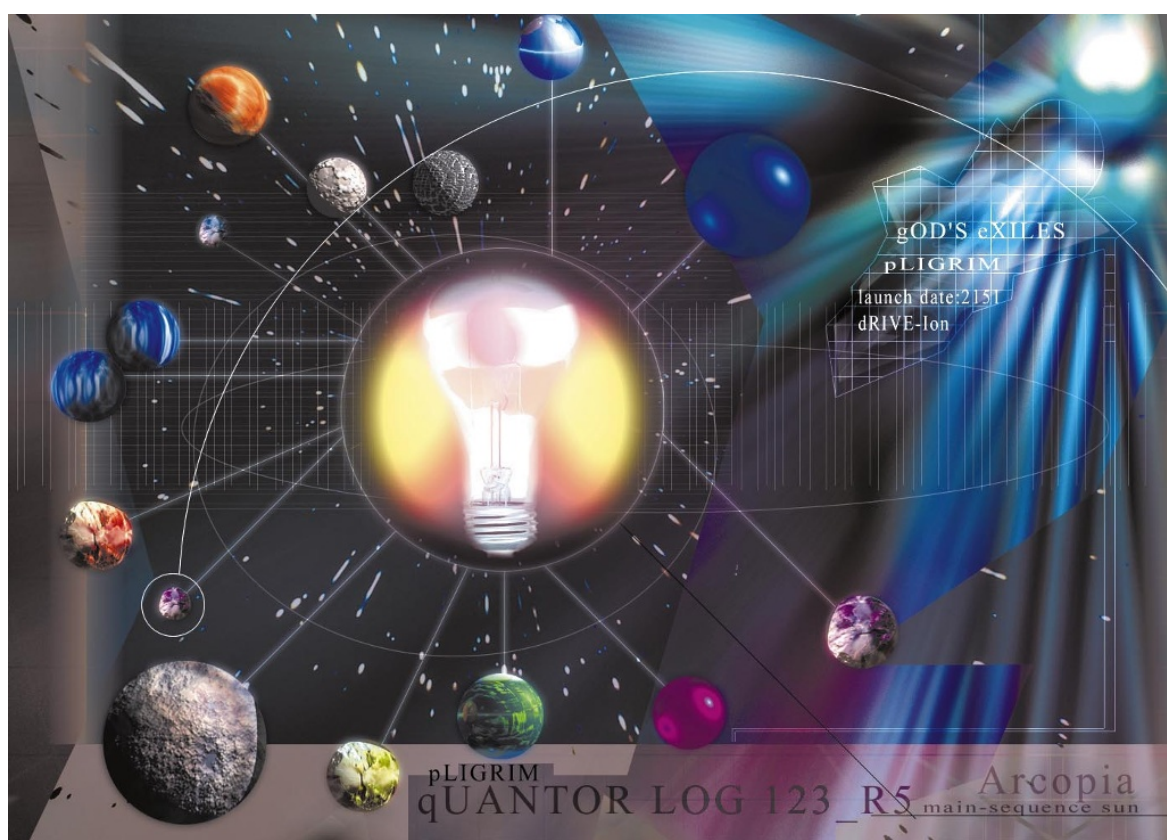

